\title{
Optimizing weaning strategies of dairy replacement calves
}

\author{
A. Bach, ${ }^{*} \dagger^{1}$ J. Ahedo, $\ddagger$ and A. Ferrer $\ddagger$ \\ *ICREA (Institució Catalana de Recerca i Estudis Avançats), 08010 Barcelona, Spain \\ †Grup de Recerca en Nutrició, Maneig, i Benestar Animal, Unitat de Remugants, IRTA (Institut de Recerca i Tecnologia Agroalimentàries), \\ 08193 Bellaterra, Spain \\ ‡Rancho Las Nieves, 50550 Mallén, Spain
}

\begin{abstract}
Two experiments were conducted to evaluate whether performance could be improved and incidence of respiratory problems decreased either by allocating 6 additional days of individual housing after weaning or by moving calves in groups before weaning at 2 different ages. The first experiment involved 320 female calves that received $2 \mathrm{~L}$ of milk replacer (MR) twice daily until $49 \mathrm{~d}$ of age, and then $2 \mathrm{~L}$ of MR once daily until weaning at $56 \mathrm{~d}$ of age. Half of the calves were allowed to remain individually housed for an additional $6 \mathrm{~d}$ after weaning, and the other half were moved immediately after weaning to a different pen holding 8 calves. The second experiment involved 240 female calves that received $2 \mathrm{~L}$ of MR twice daily until $49 \mathrm{~d}$ of age, and then $2 \mathrm{~L}$ of MR once daily. Half of the calves were moved at $49 \mathrm{~d}$ of age to superhutches holding 8 calves with an elevated trough that was used to continue delivering MR; the other half remained individually housed until the age of $56 \mathrm{~d}$ and were then moved to the superhutches, where they also continued to receive MR. Growth and incidence of respiratory problems were recorded in both experiments, and feed intake was recorded in experiment 2. Calves moved to groups immediately after weaning reached the target BW $6 \mathrm{~d}$ earlier and experienced a lesser incidence of respiratory afflictions than those grouped $6 \mathrm{~d}$ after weaning. From experiment 2, calves grouped at $49 \mathrm{~d}$ of age had a greater average daily gain and BW at $56 \mathrm{~d}$ of age as a result of a greater total solid feed consumption compared with those grouped at $56 \mathrm{~d}$ of age. Calves grouped at $56 \mathrm{~d}$, however, had a greater average daily gain between 56 and $64 \mathrm{~d}$ of age (the week following grouping for the calves in the 56-d treatment) than those grouped at $49 \mathrm{~d}$ of age. Overall, the proportion of animals affected by a respiratory problem between 49 and $112 \mathrm{~d}$ of age did not differ between treatments. However, calves grouped at $49 \mathrm{~d}$ of age had a lower number of respiratory cases than those
\end{abstract}

Received August 31, 2009.

Accepted October 13, 2009.

${ }^{1}$ Corresponding author: alex.bach@irta.es grouped at $56 \mathrm{~d}$ of age. It is concluded that moving calves from individual hutches to groups of calves in superhutches immediately after weaning is preferable to waiting an additional $6 \mathrm{~d}$. In addition, moving calves from individual hutches to groups of 8 in superhutches at $49 \mathrm{~d}$ of age and starting to reduce MR offering once grouped is preferable to starting to reduce MR while calves are individually housed.

Key words: social, intake, performance, health

\section{INTRODUCTION}

General recommendations for rearing calves consist of keeping the animals individually housed and feeding milk or milk replacer (MR) twice daily. The main purpose of housing calves individually is to minimize spread of diseases and facilitate control of starter intake. Because of increasing labor costs, 2 practices have recently been implemented: 1) sending calves to contract heifer operations, and 2) grouping calves and offering MR either manually or with automatic feeding systems (Pettersson et al., 2001). A recent survey conducted in the United States (Fulwider et al., 2008) indicated that about $50 \%$ of the producers raised their own calves and heifers, whereas the other $50 \%$ sent their replacements to specialized rearing locations. The implementation of optimized management practices that reduce the spread of diseases or build calf immunity to fight pathogens when calves are grouped is especially important in contract heifer operations where animals from different origins are commingled. A common recommendation extensively implemented in the field to minimize the incidence of diseases is to keep calves individually housed for at least 1 additional week following weaning (Quigley, 2001). However, to our knowledge, there seems to be no scientific evidence to back up such a recommendation. A study conducted at the University of Minnesota (Ziegler et al., 2008) compared performance of calves that were weaned and immediately moved to groups of 10 animals with those weaned and kept in individual hutches for an additional $14 \mathrm{~d}$; the study reported no differences in performance during the first $112 \mathrm{~d}$ following weaning. Thus, the first 
objective of this study (experiment 1) was to evaluate whether allowing calves to remain individually housed for an additional $6 \mathrm{~d}$ after weaning was beneficial in terms of improving performance and preventing respiratory problems.

Weaning time has traditionally been considered to be stressful for calves. Several studies have evaluated the effect of weaning calves in groups or individually on performance (Terré et al., 2006), behavior (Warnick et al., 1977; Keil and Langhans, 2001), and health (Svensson and Liberg, 2006; Terré et al., 2006). These studies kept the animals housed either individually or in a group throughout the study. An alternative weaning strategy would consist of keeping calves individually housed for a period of time and then forming groups of calves for another period of time and weaning them while in groups. Therefore, the second objective of this study (experiment 2) was to evaluate the effect on performance and incidence of diseases of moving calves into groups before weaning at 2 different ages.

\section{MATERIALS AND METHODS}

All feed ingredients used in the 2 experiments were analyzed for DM $\left(24 \mathrm{~h}\right.$ at $\left.103^{\circ} \mathrm{C}\right)$; ash $\left(4 \mathrm{~h}\right.$ at $\left.550^{\circ} \mathrm{C}\right)$; CP using AOAC (1990; method no. 988.05), adapted for an automatic distiller Kjeldahl (Kjeltec Auto 1030 Analyzer, Tecator, Höganäs, Sweden) and using $\mathrm{CuSO}_{4} /$ Se as a catalyst instead of $\mathrm{CuSO}_{4} / \mathrm{TiO}_{2}$; ether extract using AOAC (1990; method no. 920.39); NDF (with sodium sulfite and heat-stable $\alpha$-amylase) and ADF following Van Soest et al. (1991); and gross energy content using an adiabatic IKA-calorimeter C4000 (Janke \& Kunkel, Heitersheim, Germany).

\section{Experiment 1 (Additional Days of Isolation After Weaning)}

Animals and Treatments. The aim of this experiment was to assess whether allowing the weaned calf additional days of individual housing would result in improved animal performance and more robust health, which would allow the calf to reach a target BW (115 $\mathrm{kg}$ ) at an earlier age. To accomplish this objective, 320 female Holstein calves (initial BW $=41.4 \pm 5.43 \mathrm{~kg}$; initial age $=12.4 \pm 7.30 \mathrm{~d}$ ) were assigned to 2 treatments in 4 periods. Treatments consisted of 1) allowing calves to remain individually housed for an additional $6 \mathrm{~d}$ after weaning, and 2) moving them immediately after weaning to a different pen, forming groups of 8 contemporaneous calves.

Calves were individually housed in covered hutches $(1.1 \times 1.6 \mathrm{~m})$, which were bedded with straw once every other day. Calves had ad libitum access to water and a
Table 1. Ingredient and chemical composition (DM basis) of the milk replacer, starter, and TMR offered to calves in experiments 1 and 2

\begin{tabular}{|c|c|c|c|}
\hline Item & Milk replacer & Starter & TMR \\
\hline \multicolumn{4}{|l|}{ Ingredient, \% } \\
\hline Rye-grass & - & - & 10.0 \\
\hline Soybean meal & - & 15 & 15.2 \\
\hline Corn & - & 30.0 & 20.8 \\
\hline Barley & - & 9.0 & 20.7 \\
\hline Wheat middlings & - & 7.0 & 7.6 \\
\hline Soybean hulls & - & 7.0 & 5.3 \\
\hline Whole soybean & - & 6.0 & - \\
\hline Carob meal & - & 6.0 & - \\
\hline Oats & - & 5.0 & - \\
\hline Cookie waste & - & 4.0 & 9.1 \\
\hline Molasses & - & 4.0 & - \\
\hline Linseed meal & - & 2.0 & - \\
\hline Dry sweet whey & 18.9 & 2.0 & - \\
\hline Crude glycerin & - & - & 2.3 \\
\hline Malt sprouts & - & - & 6.3 \\
\hline Mineral-vitamin premix & - & 1.2 & 0.4 \\
\hline Dicalcium phosphate & - & 1.2 & 0.2 \\
\hline Sodium chloride & - & 0.4 & 0.2 \\
\hline Calcium carbonate & 0.1 & 0.2 & 0.9 \\
\hline Dry skim milk & 56 & - & - \\
\hline Palm oil & 10 & - & - \\
\hline Wheat starch & 8 & - & - \\
\hline Coconut oil & 7 & - & - \\
\hline \multicolumn{4}{|l|}{ Nutrient } \\
\hline $\mathrm{CP}, \%$ & 25.0 & 20.7 & 18.5 \\
\hline NDF, $\%$ & 2.0 & 20.5 & 27.5 \\
\hline $\mathrm{ADF}, \%$ & - & 9.7 & 14.5 \\
\hline Ether extract, \% & 19.2 & 3.9 & 3.6 \\
\hline Ash, $\%$ & 6.5 & 5.9 & 6.9 \\
\hline Gross energy, ${ }^{1} \mathrm{Mcal} / \mathrm{kg}$ & 4.97 & 4.47 & 4.49 \\
\hline
\end{tabular}

${ }^{1}$ Determined using an adiabatic calorimeter.

starter (Table 1) and received $2 \mathrm{~L}$ of an MR (Table 1) at $15 \% \mathrm{DM}$ twice daily (0700 and $1700 \mathrm{~h}$ ) until the age of $49 \mathrm{~d}$. At that time, calves received $2 \mathrm{~L}$ of MR only at $0800 \mathrm{~h}$ until the weaning time at $56 \mathrm{~d}$ of age.

After weaning, half of the calves were moved into groups of 8 animals for a period of $42 \mathrm{~d}$. The groups were housed in superhutches $(6 \times 3 \mathrm{~m} ; 20$ superhutches $)$ equipped with a feed bunk that provided space for 8 calves and 1 water bowl. When moved into groups, the calves continued to receive the starter. At $62 \mathrm{~d}$ of age, they were switched to a dry TMR (Table 1 ), which they were fed until $98 \mathrm{~d}$ of age. The other half of the calves were kept in individual hutches for an additional $6 \mathrm{~d}$ after weaning. During these additional $6 \mathrm{~d}$, calves continued to receive the starter but had no access to MR. At $62 \mathrm{~d}$ of age, the were moved to the superhutches for a period of $42 \mathrm{~d}$, also forming groups of 8 calves (20 superhutches). When moved to the superhutches, they were switched to the same dry TMR described previously, which they were fed until $104 \mathrm{~d}$ of age. Thus, both groups of calves were fed in the same manner throughout the experiment and all animals were monitored for $42 \mathrm{~d}$ after being grouped. 
Measurements. Animals were weighed upon arrival at the study site (about $12 \mathrm{~d}$ of age), at 56 or $62 \mathrm{~d}$ of age (when calves were moved into groups), and at the end of the study $42 \mathrm{~d}$ after grouping (at 98 or $104 \mathrm{~d}$ of age, depending on the treatment received). Incidence of respiratory afflictions was recorded daily throughout the study.

Calculations and Statistical Analyses. Total ADG was calculated by difference in BW between the beginning and the end of the study. Partial ADG were also calculated for the pre- and postweaning periods for both groups of animals. Performance data referring to the preweaning period were analyzed using a mixedeffects model with period as a random effect and treatment as a fixed effect (calf was the experimental unit). Postweaning performance data and overall ADG (from the beginning to the end of the study) were analyzed using a 2-level mixed-effects model (Rabe-Hesketh and Skrondal, 2005). Level 2 was the pen and level 1 was the calf. Thus, the model accounted for the dependence of calves within each superhutch, the random effect of period, and the fixed effect of treatment (the superhutch was the experimental unit). These analyses were conducted with SAS (version 8.02, SAS Institute, Cary, $\mathrm{NC})$.

Incidence of respiratory diseases was analyzed with similar models as described above but using mixed-effects logistic regression. These analyses were performed using Stata (Stata Corporation, 2006).

\section{Experiment 2 (Time of Socialization)}

Animals and Treatments. The objective of this experiment was to assess whether age at which calves are grouped has an effect on performance and incidence of diseases. The experiment involved 240 female Holstein calves (initial $\mathrm{BW}=42.8 \pm 4.95 \mathrm{~kg}$; initial age $=13.1$ $\pm 6.02 \mathrm{~d}$ ) that were assigned to 2 different treatments in 3 different periods. Calves were individually housed $(1.1 \times 1.6 \mathrm{~m})$, had ad libitum access to water and a starter (Table 1), and received $2 \mathrm{~L}$ of an MR (Table 1) at $12.5 \%$ DM twice daily $(0700$ and $1700 \mathrm{~h})$ until the age of $49 \mathrm{~d}$. At that time, the amount of MR offered to all calves was reduced to $2 \mathrm{~L}$ only at $0700 \mathrm{~h}$, the starter was substituted with a dry TMR (Table 1), and calves were randomly allocated to 1 the 2 treatments: 1) individually housed until $56 \mathrm{~d}$ of age and then moved to groups of 8 contemporaneous calves in superhutches $(6 \times 3 \mathrm{~m} ; 15$ superhutches $)$ with a feed bunk with space for 8 calves, 1 water bowl, and 1 elevated trough (50 $\mathrm{cm}$ from the floor) used to deliver MR to calves; or 2) immediately (49 d) moved to groups of 8 calves (15 superhutches). The trough in these superhutches had sufficient length $(205 \mathrm{~cm})$ to allow all 8 calves within each superhutch to have access to MR simultaneously.

All calves were weaned at $70 \mathrm{~d}$ of age; thus, all received MR once daily for 3 wk. One set of calves received MR in bottles for $1 \mathrm{wk}$ while individually housed and then in a trough for 2 wk while housed in groups; the other set of calves received MR in a trough for 3 wk while housed in groups. The experiment ended when calves reached $112 \mathrm{~d}$ of age. Thus, calves that were housed in groups at the time that the MR offering was reduced to 1 daily dose spent $9 \mathrm{wk}$ in groups, whereas calves in the other treatment spent 8 wk in groups. Both groups of calves were fed in the same manner throughout the experiment.

Measurements, Calculations, and Statistical Analyses. All calves were weighed upon arrival at the study site (about $13 \mathrm{~d}$ of age) and at 49, 56, 70, 77, and 112 d of age. Solid feed intake was recorded from 49 to $77 \mathrm{~d}$ of age in each period. Incidence of respiratory afflictions was recorded throughout the study until 77 d of age.

The coefficient of variation $(\mathbf{C V})$ of $\mathrm{BW}$ and $\mathrm{ADG}$ was calculated for each pen and measurement time. Feed consumption analyses were conducted on weekly average consumptions within superhutches. The superhutch was the experimental unit in this experiment. Performance and intake data were analyzed using a 3-level mixed-effects model (Rabe-Hesketh and Skrondal, 2005; Bach et al., 2009). Level 3 was the pen, level 2 was the calf, and level 1 was the occasion when measurements were obtained (repeated measure). The model accounted for the random effects of period and superhutch and the fixed effects of treatment, week of measurement, and their interaction (with week entering the model as a repeated measure). Incidence of respiratory cases was analyzed using a similar model but using mixed-effects logistic regression and Stata (Stata Corporation, 2006).

\section{RESULTS AND DISCUSSION}

Overall, 560 female Holstein calves participated in this study. Out of these calves, 2 were removed from experiment 1 because of death ( 1 from each treatment). Data from these 2 calves were not included in the analyses. No calves were removed from experiment 2.

\section{Experiment 1 (Additional Days of Isolation After Weaning)}

As expected, there were no differences in initial BW of calves (Table 2). Also as expected, and consequent of the experimental design used, BW and age of calves 
Table 2. Effect of time of grouping with respect to weaning on BW and ADG of dairy replacement calves (experiment 1)

\begin{tabular}{lcccc}
\hline Item & Grouped $6 \mathrm{~d}$ after weaning & Grouped at weaning & $\mathrm{SE}$ & $P$-value $^{1}$ \\
\hline Initial BW, kg & 41.8 & 42.4 & 0.52 & 0.51 \\
Initial age, d & 12.3 & 11.6 & 0.38 & 0.16 \\
BW before grouping, $\mathrm{kg}$ & 78.9 & 76.1 & 0.66 & $<0.001$ \\
Age before grouping, d & 61.9 & 56.1 & 0.17 & $<0.001$ \\
ADG before grouping, g/d & 749 & 758 & 12.0 & 0.49 \\
Final BW, kg & 114.5 & 113.7 & 1.04 & 0.76 \\
Final age, d & 103.9 & 98.2 & 0.29 & $<0.001$ \\
ADG after grouping, g/d & 847 & 894 & 19.9 & 0.09 \\
Overall ADG, g/d & 794 & 826 & 11.2 & 0.05 \\
\hline
\end{tabular}

${ }^{1}$ Effect of time of grouping.

when moved from individual to group housing were greater $(P<0.001)$ in those that were moved $6 \mathrm{~d}$ after weaning compared with those that were moved immediately after weaning (Table 2). There was no difference in ADG between the 2 groups of animals while individually housed.

The target final BW of this study was $115 \mathrm{~kg}$. Calves that were moved to groups immediately after weaning reached the target BW $6 \mathrm{~d}$ earlier $(P<0.001)$ than those grouped $6 \mathrm{~d}$ after weaning. This difference was caused in part by the experimental design (all animals were held for $42 \mathrm{~d}$ in groups; thus, those grouped $6 \mathrm{~d}$ after weaning left the study $6 \mathrm{~d}$ older), but it was also caused by the fact that calves that were immediately grouped following weaning tended $(P=0.09)$ to grow faster after grouping than those that were grouped $6 \mathrm{~d}$ after weaning. In fact, the overall growth performance during the entire study was greater $(P=0.05)$ for calves that were moved into groups immediately following weaning than for calves that were kept in individual hutches for an additional $6 \mathrm{~d}$.

Calves that remained individually housed for an additional $6 \mathrm{~d}$ experienced a greater $(P<0.01)$ incidence of respiratory afflictions after weaning and had more than twice-greater odds of having a respiratory case than those that were grouped immediately after weaning (Table 3). The overall odds of having a respiratory case (could be more than 1 for each animal) were 2.13 \pm 0.54 greater $(P<0.05)$ in calves that spent an additional $6 \mathrm{~d}$ individually housed than in those that were moved into groups immediately after weaning (data not shown).
These results are contrary to the common recommendation of providing the weaned calf an additional 7 to $14 \mathrm{~d}$ of individual hutching after weaning. However, to our knowledge, the only previous study that has evaluated these effects reported no differences in performance when comparing calves immediately moved after weaning with calves kept for an additional $14 \mathrm{~d}$ (Ziegler et al., 2008). An important aspect of the current study to bear in mind is that the hutches used had no opening for exercise, and calves were confined within $1.1 \times 1.6$ $\mathrm{m}$ while individually housed. Thus, a possible reason for the greater incidence of respiratory problems, and also the overall worse calf performance, observed in the calves that were weaned and kept for an additional 6 $\mathrm{d}$ in individual hutches compared with those grouped at weaning time could be that the hutch dimensions limited the environmental quality as the calf body mass increased over time. Thus, the results of the current study should be applied only to calf rearing conditions similar to the ones described herein and should be applied to other rearing conditions with caution.

\section{Experiment 2 (Time of Socialization)}

Overall, there were no differences in initial and final BW and age (Table 4). However, there were significant interactions between time and age at grouping on BW and ADG (Figure 1), and total ADG was greater $(P$ $<0.05)$ in calves moved to groups at 49 than in those moved at $56 \mathrm{~d}$ of age. At $56 \mathrm{~d}$ of age, this greater ADG resulted in a greater $(P<0.05)$ BW of calves grouped at 49 compared with those grouped at $56 \mathrm{~d}$ of

Table 3. Effect of time of grouping relative to weaning on the proportion (\%) of animals affected by respiratory afflictions and odds ratio (grouped $6 \mathrm{~d}$ after weaning vs. grouped immediately after weaning) of having a respiratory problem (experiment 1 )

\begin{tabular}{lccccc}
\hline Item & Grouped $6 \mathrm{~d}$ after weaning & Grouped at weaning & $\mathrm{SE}$ & Odds ratio & $P$-value \\
\hline Before grouping & 1.72 & 1.69 & 1.21 & 0.98 & 0.98 \\
After grouping & 61.2 & 41.4 & 4.59 & 2.24 & $<0.01$ \\
\hline
\end{tabular}

${ }^{1}$ Effect of time of grouping. 
Table 4. Growth performance and intake of calves as affected by time of socialization (experiment 2)

\begin{tabular}{|c|c|c|c|c|c|}
\hline \multirow[b]{2}{*}{ Item } & \multirow[b]{2}{*}{$\begin{array}{l}\text { Grouped at } \\
49 \mathrm{~d} \text { of age }\end{array}$} & \multirow[b]{2}{*}{$\begin{array}{l}\text { Grouped at } \\
56 \mathrm{~d} \text { of age }\end{array}$} & \multirow[b]{2}{*}{ SE } & \multicolumn{2}{|c|}{$P$-value } \\
\hline & & & & Treatment & $\begin{array}{l}\text { Treatment } \\
\quad \times \text { week }\end{array}$ \\
\hline Initial BW, $\mathrm{kg}$ & 43.1 & 42.4 & 0.45 & 0.36 & - \\
\hline Initial age, $\mathrm{d}$ & 13.9 & 12.6 & 0.91 & 0.28 & - \\
\hline Final BW, kg & 147.5 & 145.1 & 2.92 & 0.79 & - \\
\hline Final age, $\mathrm{d}$ & 111.5 & 112.3 & 0.45 & 0.24 & - \\
\hline $\mathrm{BW}, \mathrm{kg}$ & 92.7 & 91.2 & 0.95 & 0.15 & 0.05 \\
\hline $\mathrm{ADG}, \mathrm{kg} / \mathrm{d}$ & 1.07 & 1.03 & 0.016 & 0.03 & $<0.001$ \\
\hline Pen CV of BW, \% & 11.1 & 10.4 & 0.89 & 0.29 & 0.16 \\
\hline Pen $\mathrm{CV}$ of $\mathrm{ADG}, \%$ & 23.8 & 17.2 & 6.07 & 0.45 & 0.38 \\
\hline Solid feed consumption, $\mathrm{kg} / \mathrm{d}$ & 2.61 & 2.49 & 0.056 & 0.01 & 0.03 \\
\hline
\end{tabular}

age (Figure 1). Both ADG and BW increments between 49 and $56 \mathrm{~d}$ of age were the result of an increase in solid feed intake. Average total solid feed consumption was greater in calves grouped at 49 than in those grouped at $56 \mathrm{~d}$ of age (Table 4), with this difference caused mostly by a greater intake observed in calves grouped at $49 \mathrm{~d}$ of age during the first $2 \mathrm{wk}$ after being grouped (Figure 2) compared with those grouped at $56 \mathrm{~d}$ of age. Between 49 and $56 \mathrm{~d}$ of age, calves that remained individually housed consumed $220 \pm 60 \mathrm{~g} / \mathrm{d}$ less $(P<$

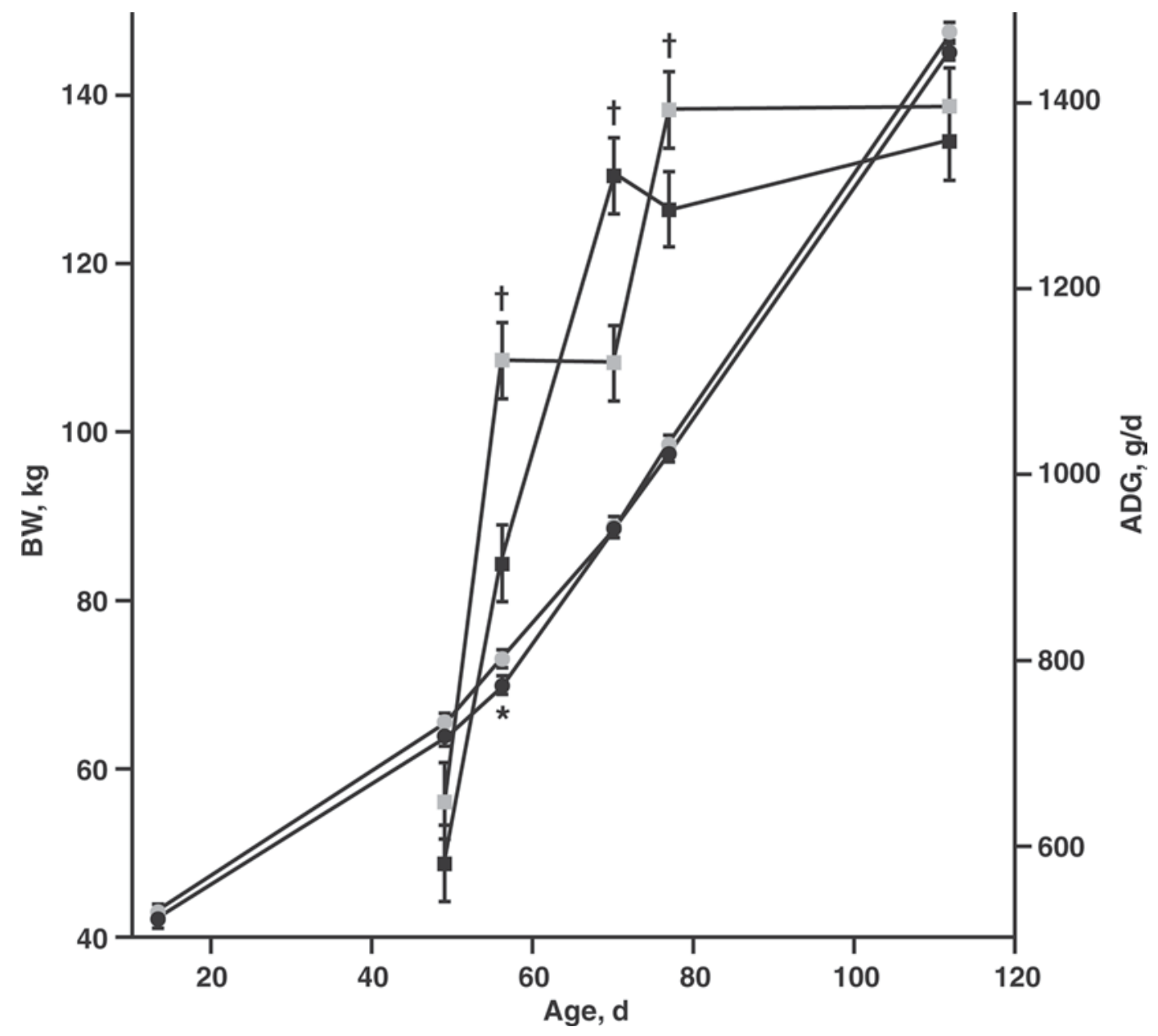

Figure 1. Evolution of BW (circles) and ADG (squares) of calves grouped at 49 (gray symbols) or at 56 (black symbols) d of age in experiment 2 . Significant differences $(P<0.05)$ between treatments within age for BW are depicted as $*$ and for ADG as $\dagger$. 
Table 5. Incidence of respiratory afflictions as affected by weaning strategy (experiment 2)

\begin{tabular}{lcccc}
\hline Item & $\begin{array}{c}\text { Grouped at } \\
49 \mathrm{~d} \text { of age }\end{array}$ & $\begin{array}{c}\text { Grouped at } \\
56 \mathrm{~d} \text { of age }\end{array}$ & $\mathrm{SE}$ & $P_{\text {-value }}{ }^{1}$ \\
\hline Proportion of calves affected, $\%$ & 25.2 & 25.8 & 4.64 & 0.91 \\
Number of cases/calf & 0.87 & 1.23 & 0.13 & 0.04 \\
\hline
\end{tabular}

${ }^{1}$ Effect of time of grouping.

0.05) than those that were grouped. When calves that were scheduled to be grouped at $56 \mathrm{~d}$ of age were moved into the superhutches, feed consumption increased but did not match the level of feed consumption of the calves that had already been grouped for $1 \mathrm{wk}$; these animals tended $(P<0.10)$ to consume about $110 \pm$ $61 \mathrm{~g} / \mathrm{d}$ more than those that were recently grouped. Calves that were grouped at $56 \mathrm{~d}$ of age, however, had a greater ADG between the age range from 56 to $64 \mathrm{~d}$ of age (the week following grouping for the calves in the 56-d treatment) than those grouped at $49 \mathrm{~d}$ of age. Calves that were grouped at $56 \mathrm{~d}$ of age and continued to receive 1 dose of MR drastically (an additional 730 $\mathrm{g} / \mathrm{d}$ ) increased the consumption of solid feed, which resulted in an increased ADG that was greater than that observed in contemporaneous calves that had been grouped at $49 \mathrm{~d}$ of age (Figure 1). Solid feed increments in the remaining weeks were always below $630 \mathrm{~g} / \mathrm{d}$. The hypothetical increase in solid feed intake when grouping calves at $49 \mathrm{~d}$ of age could not be assessed in the current study because monitoring of feed intake started when calves reached $49 \mathrm{~d}$ of age.

The greater solid feed intake observed between 49 and $56 \mathrm{~d}$ of age in calves grouped at 49 versus those grouped at $56 \mathrm{~d}$ of age, and the increase in solid feed intake observed when moving calves from individual hutches to groups at $56 \mathrm{~d}$ of age, could be the consequence of 2 factors: 1) that the environment within the individual hutches was less than adequate and negatively influenced intake, or 2) that forming groups of 8 contemporaneous animals at $56 \mathrm{~d}$ of age elicited an improvement in the well-being of calves and that social facilitation fostered an increase in intake. Increases in solid feed intake when grouping calves through social facilitation have been described previously in the literature (Phillips, 2004), and a recent study (Færevik et al., 2007) reported that grouping calves in groups of 8 or 16 animals is preferable to forming small groups because the social interactions among pen mates are improved. Thus, it is likely that in the current study social facilitation played a role in promoting an increased intake (and therefore performance also increased).

Offering MR in groups did not result in differences in BW or ADG among animals within superhutch or pen (Table 4). Changes in BW or ADG of different calves within the same superhutch might have suggested a problem of competition for MR or solid feed and differences in consumption of these resources. However, as indicated by the lack of differences in the $\mathrm{CV}$ of $\mathrm{BW}$ and $\mathrm{ADG}$, it is safe to assume that calves within each superhutch received a similar amount of nutrients and thus performed in a similar fashion.

Cross-sucking might be a problem when grouping calves (Keil and Langhans, 2001), especially when MR is offered in a bucket or a trough (de Passillé, 2001; Jensen and Budde, 2006). Although cross-sucking was not specifically measured in the current study, calves were observed on a daily basis immediately after offering the MR and in the afternoon and no incidence of cross-sucking was detected. Roth et al. (2008) recently reported that cross-sucking is greatly reduced when weaning is adequate and animals consume more than $700 \mathrm{~g} / \mathrm{d}$ of solid feed. Calves in the current study were preweaned (1 daily dose of MR) with a much greater intake, which could also explain why inter-sucking was not a problem.

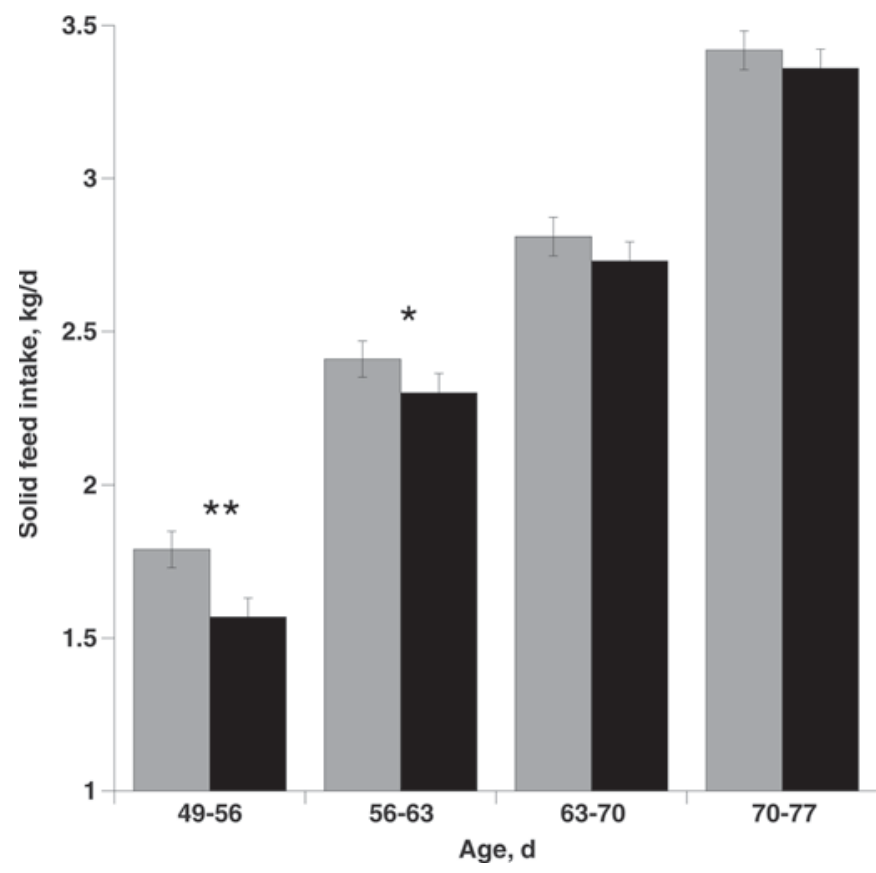

Figure 2. Solid feed intake of calves grouped at 49 (gray bars) or at 56 (black bars) d of age in experiment 2. Significant differences $(P$ $<0.05)$ or tendencies $(P<0.10)$ between treatments within age range are depicted as $* *$ or $*$, respectively. 
The incidence (\% of animals affected) of respiratory afflictions between 49 and 112 d of age did not differ between treatments (Table 5). However, calves that were grouped at $49 \mathrm{~d}$ of age had a lower number $(P<0.05)$ of respiratory cases than those grouped at $56 \mathrm{~d}$ of age (Table 5); $20 \%$ of calves grouped at $49 \mathrm{~d}$ of age had more than 1 respiratory problem, whereas $34 \%$ of calves grouped at $56 \mathrm{~d}$ of age had more than 1 respiratory case (data not shown). Again, these results indicate that health was improved when the reduction of the MR offering to 1 daily dose occurred when calves were moved to groups at $49 \mathrm{~d}$ of age compared with when the reduction of the MR offering occurred when calves were individually hutched.

\section{CONCLUSIONS}

Moving calves from individual hutches to groups of calves in superhutches immediately after weaning instead of waiting an additional $6 \mathrm{~d}$ improves overall growth performance and halves the risk of calves experiencing respiratory afflictions after weaning. Furthermore, moving calves from individual hutches to groups of 8 calves in superhutches at $49 \mathrm{~d}$ of age and starting to reduce MR offering once grouped results in greater solid feed intake and growth performance as well as improved health condition compared with starting to reduce MR offering at $49 \mathrm{~d}$ of age while calves are individually housed. Thus, it is recommended to move calves into groups at $49 \mathrm{~d}$ of age and then reduce MR offering.

\section{ACKNOWLEDGMENTS}

The authors thank the Spanish Ministry of Industry, Tourism, and Trade (Madrid, Spain) through the CDTI (Centro para el Desarrollo Tecnológico Industrial) for partial funding of these studies through the project number IDI-20080836. Also, a special thanks to Vicente García (Rancho Las Nieves, Mallén, Spain) for his pivotal role in the organization and combination of routine activities of Rancho Las Nieves and the tasks imposed by these research studies, and to Ana Ramillete (also of Rancho Las Nieves) for her meticulous assistance with data handling.

\section{REFERENCES}

AOAC. 1990. Official Methods of Analysis. 15th ed. Association of Official Analytical Chemists, Arlington, VA.

Bach, A., M. Devant, C. Igleasias, and A. Ferrer. 2009. Forced traffic in automatic milking systems effectively reduces the need to get cows, but alters eating behavior and does not improve milk yield of dairy cattle. J. Dairy Sci. 92:1272-1280.

de Passillé, A. M. 2001. Sucking motivation and related problems in calves. Appl. Anim. Behav. Sci. 72:175-187.

Færevik, G., I. L. Andersen, M. B. Jensen, and K. E. Bøe. 2007. Increased group size reduces conflicts and strengthens the preference for familiar group mates after regrouping of weaned dairy calves (Bos taurus). Appl. Anim. Behav. Sci. 108:215-228.

Fulwider, W. K., T. Grandin, B. E. Rollin, T. E. Engle, N. L. Dalsted, and W. D. Lamm. 2008. Survey of dairy management practices on one hundred thirteen north central and northeastern United States dairies. J. Dairy Sci. 91:1686-1692.

Jensen, M. B., and M. Budde. 2006. The effects of milk feeding method and group size on feeding behavior and cross-sucking in grouphoused dairy calves. J. Dairy Sci. 89:4778-4783.

Keil, N. M., and W. Langhans. 2001. The development of intersucking in dairy calves around weaning. Appl. Anim. Behav. Sci. 72:295308.

Pettersson, K., C. Svensson, and C. Liberg. 2001. Housing, feeding and management of calves and replacement heifers in Swedish dairy herds. Acta Vet. Scand. 42:465-478.

Phillips, C. J. C. 2004. The effects of forage provision and group size on the behavior of calves. J. Dairy Sci. 87:1380-1388.

Quigley, J. 2001.Calf note \#16-Stress at weaning. http://www. calfnotes.com/pdffiles/CN016.pdf July 15, 2009

Rabe-Hesketh, S., and A. Skrondal. 2005. Multilevel and Longitudinal Modeling Using Stata. Stata Press, College Station, TX.

Roth, B. A., E. Hillmann, M. Stauffacher, and N. M. Keil. 2008. Improved weaning reduces cross-sucking and may improve weight gain in dairy calves. Appl. Anim. Behav. Sci. 111:251-261.

Stata Corporation. 2006. Stata/SE 9.2 for Macintosh. StataCorp, College Station, TX.

Svensson, C., and P. Liberg. 2006. The effect of group size on health and growth rate of Swedish dairy calves housed in pens with automatic milk-feeders. Prev. Vet. Med. 73:43-53.

Svensson, C., K. Lundborg, U. Emanuelson, and S. O. Olsson. 2003 Morbidity in Swedish dairy calves from birth to 90 days of age and individual calf-level risk factors for infectious diseases. Prev. Vet. Med. 58:179-197.

Terré, M., A. Bach, and M. Devant. 2006. Performance and behavior of calves reared in groups or individually following an enhancedgrowth feeding program. J. Dairy Res. 73:480-486.

Van Soest, P. J., J. B. Robertson, and B. A. Lewis. 1991. Methods for dietary fiber, neutral detergent fiber, and nonstarch polysaccharides in relation to animal nutrition. J. Dairy Sci. 74:3583-3597.

Warnick, V. D., C. W. Arave, and C. H. Mickelsen. 1977. Effects of group, individual, and isolated and rearing of calves on weight gain and behavior. J. Dairy Sci. 60:947-953.

Ziegler, D., B. Ziegler, M. Raeth-Knight, R. Larson, G. Golombeski, J. Linn, and H. Chester-Jones. 2008. Performance of post weaned Holstein heifer calves transitioned to group housing using different management strategies while fed a common diet. J. Dairy Sci. 86:465. (Abstr.) 